\title{
Governança Corporativa: Estudo dos Motivos Que IMPEDEM a Ades̃̃o das COMPANHIAS Abertas ao Novo Mercado da Bovespa
}

\author{
Prof. Dr. João Bosco Segreti \\ Centro Universitário Álvares Penteado-UniFECAP \\ segreti@fecap.br
}

\author{
Prof. Dr. Gregório Mancebo Rodriguez \\ Universidade ANHEMBI-MORUMBI \\ gregóri@@mimec.com.br \\ Prof. Ivam Ricardo Peleias \\ Professordo Mestrado em Ciências Contábeis- \\ FECAP - São Paulo \\ ivamrp@fecap.br
}

RESUMO

O desenvolvimento do mercado de capitais tem levado os investidores a exigir, cada vez mais, que as empresas utilizem as boas práticas de governança corporativa. No entanto, o número de empresas que aderiram aos segmentos do Novo Mercado da Bolsa de Valores do Estado de São Paulo - Bovespa, ainda é relativamente baixo. Neste contexto, o objetivo deste estudo é verificar quais são os motivos que impedem as empresas de aderirem a estes mercados. Para tanto, foi realizada uma pesquisa empírica junto a trinta especialistas de empresas com ações negociadas na Bovespa que representavam $76 \%$ do valor do patrimônio líquido negociado. Os resultados obtidos indicam que são os custos implícitos, aqueles decorrentes do compartilhamento do poder dos controladores com os acionistas que não detém o controle acionário, a verdadeira causa desta baixa adesão aos novos mercados da Bovespa.

Palavras-Chave: Custos, Ações, Governança Corporativa, Novo Mercado BOVESPA, Companhias Abertas
The development of the capital markets has driven the investors to moreand more require the companies to put to use the corporate governancegood practices. However, the number of companies that adhered to the segments New Market at Bolsade Valores do Estado de São Paulo-Bovespa, is still relatively low. In this context, the goal of this study is to examine the reasons that impede the companies tojoin these new markets. Therefore, an empirical research bas been conducted, aiming at the companies'specialists who already have had stocks traded at Bovespa. The obtained results indicate that the implicit costs, that are those resulting from the sharing of the controllers' powerwith thestockbolders, those who donot bold the stocks' control are the true causers of the low adhesion to Bovespa's New Markets.

KEYWORDs: Costs, Stocks, Corporate Governance, Bovespa's Nerw Market, Opened Companies. 


\section{INTRODUÇÃO}

Nos últimos anos tem-se assistido, no mundo corporativo a inusitadas mudanças ocasionadas por diversos fatores, entre os quais pode-se destacar: a expansão das empresas além de seus territórios de origem globalização; o desenvolvimento econômico, social dos países onde estão instaladas suas subsidiárias; a maior complexidade da composição societária das grandes empresas; o grande volume de fusões, aquisições e incorporações de empresas; a expansão dos fluxos de recursos decorrente do mercado de capitais; e as questões de ética empresarial, envolvendo conflitos entre empresa e acionistas.

Para Soares (2002, p.259), estas mudanças ocasionaram uma enorme revolução, pois as condições históricas de desempenho das empresas nunca estiveram sujeitas à ocorrência de tamanha quantidade de mudanças radicais em tão curto espaço de tempo.

As empresas do século XXI convivem com as mudanças que ocorrem nos mercados consumidores, internos ou externos. Necessitam estar aptas a colocar seus produtos junto ao público consumidor no menor espaço de tempo possível, na quantidade e com a qualidade desejadas, e com os menores custos de produção; concorrer com vários participantes dos mais diversos países, que disputam os mesmos mercados. Porém, não basta ser eficiente e lucrativa, a empresa passa a ser julgada, também, por outros ângulos, tais como os da governança corporativa e da responsabilidade ambiental e social.

A governança corporativa diz respeito à forma como uma empresa está sendo administrada; estpa relacionada com a liderança, estratégia e política empresarial. Estuda os relacionamentos de poder dentro da companhia e trata das melhores práticas que devem norteá-los. A Organization for Economic Cooperation and Development - OECD (1999) a define como o sistema segundo o qual as corporações de negócio são dirigidas e controladas.

Neste sentido, os investidores têm exigido, cada vez mais, que as empresas adotem boas práticas de governança corporativa, passando a ser avaliadas não somente pelo seu desempenho financeiro, mas, também, pela transparência de suas operações, responsabilidades social e ambiental e pelas políticas de remuneração aos seus acionistas.

A moderna gestão empresarial tem dado ênfase especial ao conceito da criação de valor para o acionista. Não é suficiente, apenas, uma boa gestão de custos, ou produtos que atendam à conformidade de produção visando às necessidades do consumidor, cada vez mais exigente. As decisões dos gestores devem estar embasadas em um sistema eficiente de informações, obtidas através da contabilidade, atendendo ao princípio da continuidade da entidade, e visando o enfoque voltado à agregação de valor e criação de riqueza para os acionistas.

Dentro desse contexto, pode-se situar a governança corporativa no Brasil em contraposição à forma como ela se apresenta em países que possuem mercados de capitais mais avançados. Entre os vários modelos e visões de governança existentes, no Brasil, nota-se maior presença do modelo financeiro, com ênfase na visão da empresa familiar. No moderno capitalismo, e, principalmente, nos mercados de capitais mais desenvolvidos, as empresas têm procurado compartilhar a propriedade do capital como forma de obter recursos de investimento, a custos menores do que os obtidos junto a instituições de crédito.

A figura a seguir demonstra uma visão organizacional, onde a governança corporativa faz parte da estrutura estratégica juntamente com as crenças e valores e a missão da empresa.

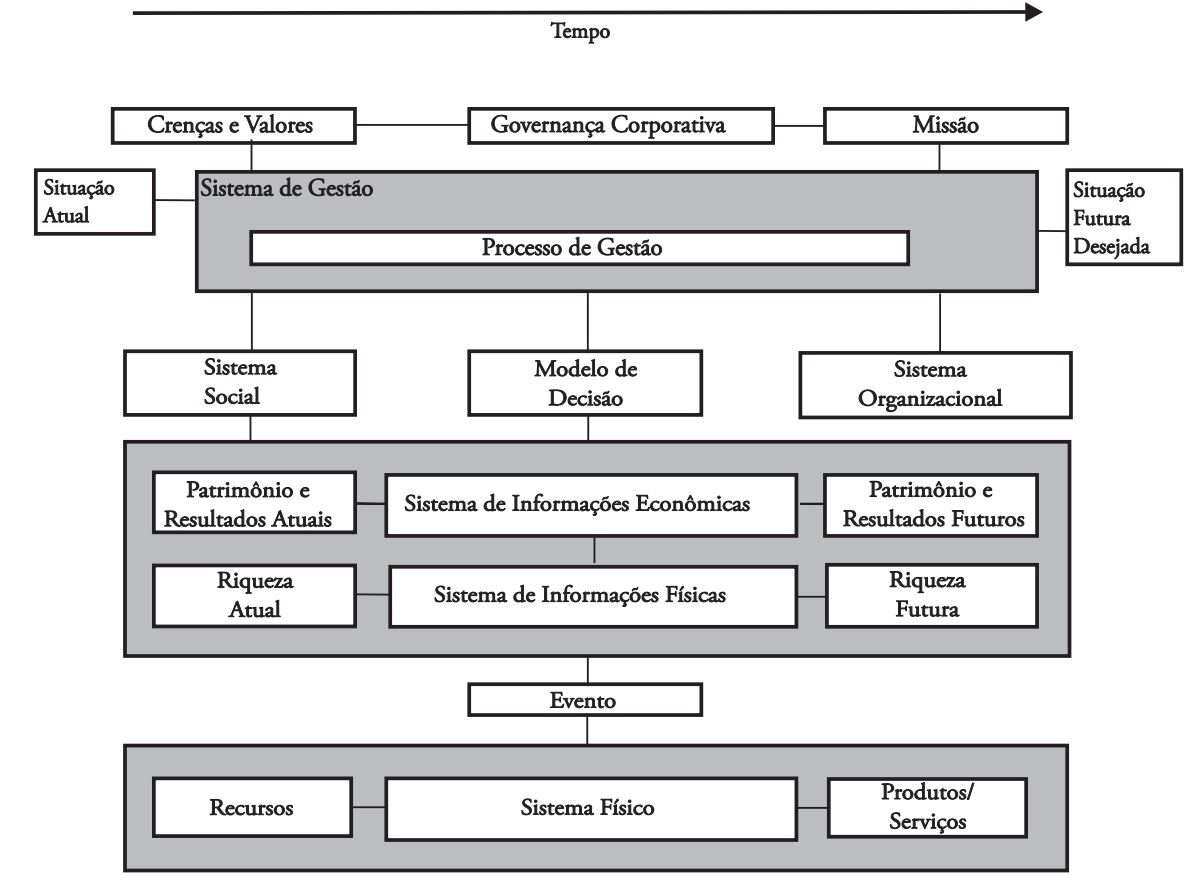

Figura 1: Visão da Organização

Fonte: Catelli (1999) 


\subsection{Abordagem sobre o tema}

Os mercados de capitais, nacional e internacional, têm exigido, de forma crescente, que as sociedades anônimas de capital aberto adotem a implementação de boas práticas de governança corporativa. Em 01/12/2000, através das resoluções $n^{\circ}$.s 264 e 265 do Conselho de Administração da Bovespa, foram criados o "Novo Mercado" e os "Níveis Diferenciados de Governança Corporativa I e II", novos segmentos de negociação de ações. Ambos acabaram sendo identificados pelos investidores apenas como "Novo Mercado", com o objetivo de incentivar as companhias abertas brasileiras a adotarem as boas práticas de governança corporativa.

No Brasil, contudo, segundo a Bovespa (2005), de cerca de 400 companhias de capital aberto, listadas no mercado acionário brasileiro, somente $15 \%$ delas aderiram a um dos níveis de governança corporativa do Novo Mercado (níveis I, II e Novo Mercado) daquela bolsa.

Desta forma, face à importância que a governança corporativa vem assumindo globalmente em contraposição com o baixo nível de adesão verificado no Brasil, o presente artigo tem por objetivo analisar quais são os motivos que impedem as empresas de aderirem a estes novos mercados da Bovespa.

\section{REFERENCIAL TEÓRICO}

No levantamento bibliográfico sobre o assunto a ser investigado foram utilizados artigos publicados em periódicos especializados, teses de doutoramento, dissertações de mestrado e informações obtidas via Internet.

\subsection{Conceituação da Governança Corporativa}

O termo "Governança Corporativa" foi derivado do termo em inglês Corporate Covernance. Yamamoto e Almeida Prado (2003, p.42) afirmam que já se observava, em 1960, a utilização do termo corporate governance no sentido de orientação das políticas de estrutura e funcionamento das empresas, e que mal traduzido para o português acabou por se consagrar como governança corporativa.

A evolução dos mercados de capitais internacionais, e a necessidade do full disclosure, para garantir acesso às informações a todos os públicos interessados também denominados stakebolders, levou à popularização do termo "Governança Corporativa", utilizado de forma ampla, porém nem sempre entendido corretamente pelos seus usuários, pois trata-se de um tema complexo.

Segundo Lodi (2000, p.19) denomina-se Governança Corporativa o papel que os Conselhos de Administração passaram a exercer para melhorar o ganho dos acionistas e arbitrar os conflitos existentes entre acionistas, administradores, auditores externos, minoritários, conselhos fiscais (no Brasil) e os stakeholders: empregados, credores e clientes.

Para OECD apud Andrade e Rossetti (2004, p.23 e 24) a governança corporativa é o sistema segundo o qual as corporações de negócio são dirigidas e controladas. A estrutura da governança corporativa especifica a distribuição dos direitos e responsabilidades entre os diferentes participantes da corporação, tais como o conselho de administração, os diretores executivos, os acionistas e outros interessados, além de definir as regras e procedimentos para a tomada de decisão em relação a questões corporativas. E oferece também bases através das quais os objetivos da empresa são estabelecidos, definindo os meios para se alcançarem tais objetivos e os instrumentos para se acompanhar o desempenho.

Segundo o Instituto Brasileiro de Governança Corporativa - IBGC (2005) a governaça pode ser definida como o sistema pelo qual as sociedades são dirigidas e monitoradas, envolvendo os relacionamentos entre Acionistas e Cotistas, Conselho de Administração, Diretoria, Auditoria Independente e Conselho Fiscal. As boas práticas de governança corporativa têm a finalidade de aumentar o valor da sociedade, facilitar seu acesso ao capital e contribuir para a sua perenidade.

A Comissão de Valores Mobiliários - CVM (2002) define em sua cartilha que Governança Corporativa é o conjunto de práticas que têm por finalidade otimizar o desempenho de uma companhia ao proteger todas as partes interessadas, tais como: investidores, empregados e credores, facilitando o acesso ao capital. A análise das práticas de governança corporativa aplicada ao mercado de capitais envolve, principalmente: transparência, eqüidade de tratamento dos acionistas e prestação de contas.

Finalmente, segundo Steinberg (2003, p.18), na definição usual, governança corporativa constitui o conjunto de práticas e de relacionamentos entre acionistas, cotistas, conselho de administração, diretoria executiva, auditoria independente e conselho fiscal com a finalidade de aprimorar o desempenho da empresa e facilitar o acesso ao capital.

Dos vários enfoques citados, pode-se extrair uma série de conceitos que estão entrelaçados, mas que, na prática, remetem a relação entre propriedade e gestão, à forma de governar a empresa e à transparência das suas atitudes, observadas pelos diversos públicos relacionados, e que se encontram sintetizadas no texto do Relatório Cadbury, citado por Lodi (2000, p.24), como "o sistema pelo qual as companhias são dirigidas e controladas". Esse sistema coloca os conselheiros de administração no centro de qualquer discussão sobre governança corporativa, conforme a figura a seguir: 


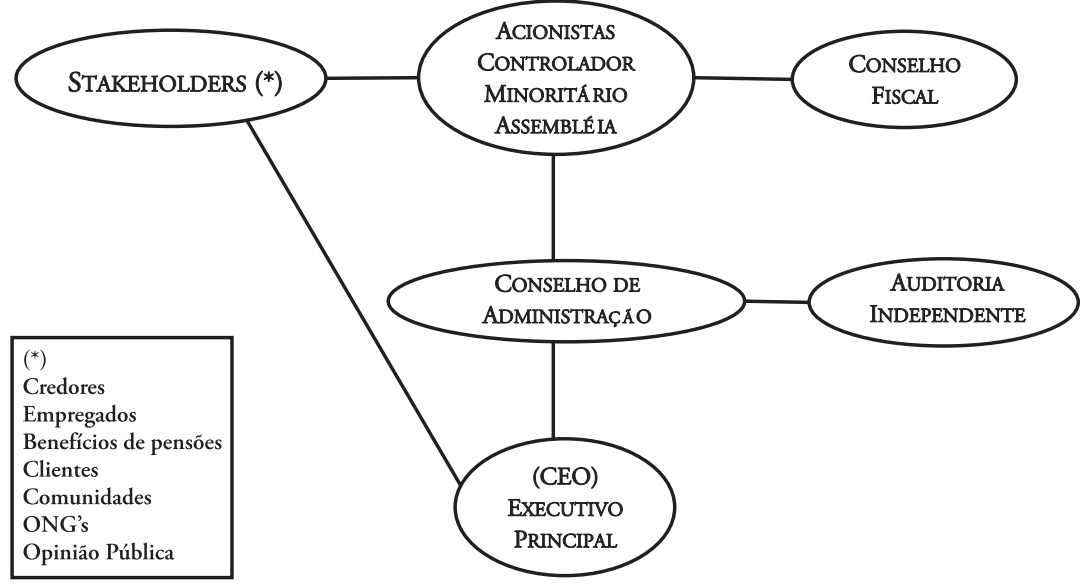

Figura 2: Governança Corporativa e o Conselho de Adminsitração Fonte: Lodi $(2000$, p.25)

\subsection{Evolução da Governança Corporativa}

O movimento pela Governança Corporativa tornouse visível a partir de 1990; contudo, sua origem remonta ao movimento que se seguiu após a $2^{a}$ Guerra Mundial, quando várias empresas lançaram ações no mercado de capitais americano, com o intuito de financiar o desenvolvimento de suas atividades, mudando, assim, a estrutura de capital vigente nas grandes corporações, que até então era centrada na figura de controle único ou de famílias que eram possuidoras da totalidade das ações.

O compartilhamento da propriedade acionária gerou um forte movimento, por parte dos investidores, visando assegurar maior participação nas decisões e assegurar direitos aos investidores não controladores (minoritários). Em algumas empresas a "pulverização" do capital foi tão disseminada, que tornava difícil identificar uma ou mais pessoas que, em conjunto, detivessem o controle acionário e pudessem responder legalmente pelas companhias.

Esta situação levou a Security Exchange Comission -SEC, órgão responsável pela regulação do mercado americano de capitais, a intervir a favor dos investidores, estipulando algumas salvaguardas a serem adotadas pelas empresas. Estas salvaguardas acabaram levando as empresas a criarem estruturas de comando e à contratação de profissionais para assumir a gestão das companhias. A concentração excessiva de poder nas mãos de alguns gestores levou a distorções, principalmente nos sistemas de remuneração de algumas empresas (bônus de participação, remuneração por desempenho), que, por sua vez, viram seus objetivos distorcidos pelos gestores, mais interessados em maximizar seus resultados (stock options), em detrimento do retorno dos acionistas.

Wald (2002, p.63) comenta esse período relatando que após a Segunda Guerra Mundial as dimensões das empresas aumentaram muito e algumas delas passaram a ter orçamentos superiores aos de alguns pequenos países. Em virtude da pulverização das ações, as diretorias passaram a ter grande autonomia, atuando, algumas vezes, conforme seu próprio interesse e não no interesse da sociedade. Além disso, devido ao conhecimento especializado necessário para a gestão dessas empresas, formou-se uma verdadeira casta, que Galbraith chamaria de tecnoestrutura.

Segundo Carlsson (2001, p.21), o movimento pela governança corporativa eclodiu nos EUA em meados da década de 80 . Houve um grande movimento de compra de ações alavancadas e de aquisição hostil do controle acionário de empresas. Em 1984, o Conselho de Administração da Texaco, utilizou uma prerrogativa legal estadunidense- $\mathrm{o}$ American Companies $A c t$, para recomprar ações da companhia a um valor substancialmente maior que o valor de mercado (ágio), de modo a evitar sua aquisição de forma hostil por parte de um acionista minoritário denominado Bass Brothers, visto como uma ameaça à posição corporativa de diretores e conselheiros da empresa. O ágio pago pela Texaco aos acionistas da Bass atingiu a cifra de US\$137 milhões, com reflexo no caixa e nos resultados da companhia refletindose negativamente, portanto, no preço das ações, tendo os acionistas minoritários como maiores prejudicados.

Um dos principais fundos de pensão americano, California Public Employes Retirement System (CalPERS), deflagrou o início de 1985 um movimento para que as empresas nas quais ele participava acionariamente adotassem medidas que resguardassem os interesses dos acionistas minoritários. O CalPERS passou a adotar uma postura mais ativa, participando de reuniões de Conselho de Administração das empresas com o intuito de defender seus interesses, usando a sua força política para aprimorar questões afetas aos minoritários e ao mercado de capitais.

Carlsson (2001) observa que o CalPERS não modificou sozinho a governança corporativa nos EUA; juntaramse ao novo movimento pela governança corporativa, entidades como o State of Wisconsin Investment Board(SWIB) eo College Retirement Fund (CREF) - um fundo de pensão cooperativo de professores, que culminou com a criação do Council of Institutional Investors (CII), em 1985, que pode ser considerado o marco inicial da governança corporativa nos EUA e no mundo, que trabalha em prol dos acionistas visando alterar a legislação americana e proteger seus interesses. Com os recentes escândalos ocorridos, principalmente, nos Estados Unidos onde o caso de maior destaque foi o da empresa Wordcom, este movimento intensificou-se e acabou resultando na edição da Lei Sarbanes-Oxley em 2002.

No Brasil, o movimento é mais visível nas companhias abertas com ações negociadas na Bovespa, porém o nú- 
mero de adesões ainda é muito baixo. Segundo a Bovespa (2005), de cerca de 400 companhias de capital aberto, listadas no mercado acionário brasileiro em 31.12 .04 , somente $12 \%$ delas aderiram a um dos níveis de governança corporativa do Novo Mercado (níveis I, II e Novo Mercado) daquela bolsa.

\subsection{Governança Corporativa no Brasil}

No Brasil, a evolução da governança corporativa enfrentou, inicialmente, certa resistência em razão dos aspectos culturais originados de uma tradição latifundiária de parte do empresariado e dos políticos brasileiros, que acabaram levando à concentração do capital na mão de poucos e da dificuldade de compartilhar o poder decisório com outros acionistas. De fato, ao invés da grande dispersão verificada nos Estados Unidos, o Brasil praticamente não possuía um mercado de capitais desenvolvido, até a década de 60. As empresas nacionais ou eram estatais ou pertenciam a grandes grupos de famílias privilegiadas.

Wald (2002, p.67) comenta que no Brasil, até 1960, não se teve um verdadeiro mercado de capitais. Não existia governo da empresa, como, em certo sentido, não havia uma democracia efetiva em nosso país até 1945 . Na época, o acionista majoritário tinha um poder arbitrário, que exercia como verdadeiro ditador. Os eventuais conflitos tinham soluções domésticas, abrangendo desde a conciliação até a utilização da força bruta. Dominava o coronelismo, tanto no plano político quanto econômico, de modo que podemos até afirmar que o direito não se aplicava, na maioria dos casos, aos conflitos societários, como, na época, não incidia nas divergências familiares, que raramente chegavam aos tribunais.

Ainda hoje prevalece uma estrutura de controle rigidamente concentrada, sendo poucas as empresas de propriedade dispersa, prevalecendo um controle marcadamente concentrado nas mãos de um grupo definido, seja nacional, seja estrangeiro, ou mesmo o próprio governo. Diante dessa realidade, não basta importar modelos prontos de corporate governance que não se ajustariam às necessidades do mercado brasileiro de capitais.

A baixa dispersão acionária vem favorecer o controle familiar das empresas. Ainda hoje, é possível encontrar, a gestão e a propriedade concentradas nas mãos do grupo controlador, e as principais funções administrativas são executadas por membros ligados à família ou a esse grupo.

Segundo Gorga (2003, p 66) a classe dominante brasileira ainda mantém valores e tradições da casa grande (senzala) em suas organizações de negócios, e os empreendedores nacionais enfrentam o dilema da manutenção do controle e a maximização do valor econômico. Ainda segundo a autora os controladores das firmas nacionais são freqüentemente identificados como a grande barreira às mudanças.

A evolução histórica da governança corporativa no Brasil registrou um grande avanço com a edição das Leis
6.404 e 6.385, ambas em 1976. Segundo Wald (2002, p.68) o primeiro diploma definiu uma série de conceitos inerentes a uma administração clara e confiável, tais como, a responsabilidade do acionista controlador, a composição e competência do conselho de administração, a possibilidade de voto cumulativo, o que dá ensejo, em tese, à presença de minoritários no Conselho de Administração, a regulamentação do direito de recesso e de saída conjunta, bem como a execução específica do acordo de acionistas. A segunda lei criou a Comissão de Valores Mobiliários, órgão que se tornou responsável pela regulação do mercado de capitais.

Pode-se notar que os princípios básicos da governança corporativa já estavam expressos em lei desde 1976. Como explicar, então, que somente a partir de 2001, as empresas nacionais passaram a dar maior importância a governança corporativa? A verdade é que não basta a previsão formal dos direitos se não houver uma exigência do mercado, ou se as empresas não sentissem a necessidade de colocá-la em prática, visando alguma vantagem empresarial.

Outro fato relevante foi o grande programa de privatizações patrocinado pelo governo brasileiro na década de 90. A abertura da economia visava recuperar o atraso proveniente da condução estatal das principais companhias, ocasionado pela falência do Estado empreendedor, e, ao mesmo tempo, promoveu um salto qualitativo no mercado de capitais e na governança corporativa.

\subsection{Principais fundamentos da Governança Corporativa}

Pode-se dizer que, atualmente, uma empresa eficiente é aquela que possui bons padrões de governança corporativa, e que consegue transmití-los a todos seus stakeholders. Não basta ter um bom produto que atenda aos requisitos exigidos pelos seus consumidores. É necessário, também, que a empresa seja socialmente responsável, seus produtos devem ser produzidos dentro de critérios de não agressão ao meio ambiente; seus funcionários devem ter condições de trabalho adequadas e acesso à alimentação, saúde e transporte; a coletividade próxima às instalações da empresa deve estar inserida nos programas de inclusão social; tudo isto sem perder de vista a razão principal de ser da empresa: remunerar condizentemente o capital dos acionistas investido na empresa, ou seja, obter lucro.

Segundo Andrade e Rossetti (2004, p.26), os elementos da governança corporativa são fundamentados em um sistema definido de valores que rege os mecanismos da gestão das empresas e as relações entre as partes interessadas nos seus resultados.

De acordo com Lodi (2000, p.24), a boa governança corporativa é assegurada aos sócios por quatro elementos-chave:

Fairness: senso de justiça, eqüidade no tratamento dos acionistas. Respeito aos direitos dos minoritários, por partici- 
pação equânime com a dos majoritários, tanto no aumento da riqueza corporativa, quanto nos resultados das operações, quanto ainda na presença ativa em assembléias gerais.

Disclosure: transparência das informações, especialmente das de alta relevância, que impactam os negócios e que envolvem riscos.

Accountability: prestação responsável de contas, fundamentada nas melhores práticas contábeis e de auditoria.

Compliance: Conformidade no cumprimento de normas reguladoras, expressas nos estatutos sociais, nos regimentos internos e nas instituições legais do país.

Steinberg (2003, p.19) denomina os quatro elementos-chave como os princípios fundamentais da boa governança e acrescenta um quinto, etbics (ética).

\subsubsection{A interação entre as partes relacionadas}

A distinção entre acionistas e gestores é crucial, principalmente quando há a pulverização da propriedade acionária. Segundo Andrade e Rossetti (2004, p.27-29), é através das boas práticas de governança que se podem minimizar os conflitos de agência. Estes ocorrem quando o agente principal (no caso, o acionista) delega ao agente executor (no caso, a direção executiva da corporação) as decisões que maximizarão os resultados das operações da empresa, em benefício do acionista; mas comportamentos oportunistas do executor podem conflitar com o objetivo do agente principal. E os conflitos ampliam-se e tornam-se mais complexos quando, além de proprietários e gestores, outras partes interessadas, internas e externas, são alcançadas pelos propósitos corporativos.

Andrade e Rossetti (2004, p.29) afirmam que a definição de propósitos estratégicos também envolve estreita interação entre os acionistas, conselhos de administração e direção executiva. Nas grandes corporações, as expectativas dos acionistas e as políticas básicas da empresa são definidas no nível corporativo, por relações entre os acionistas e os que os representam nos conselhos de administração. Daí são derivadas as diretrizes estratégicas para os negócios e para a gestão, desenvolvidas pela direção executiva e apresentadas, de volta, ao conselho, para homologação. Outro elemento também apontado por estes autores é a estrutura de poder dentro da organização, com foco em três aspectos de grande relevância: inicialmente a clara definição dos papéis dos acionistas, do conselho e da direção, bem como do que cada uma destas partes espera das duas outras; depois a definição de regras de convivência que tornem o processo decisório uma espécie de "jogo compartilhado" e finalmente o planejamento das sucessões.

O último elemento-chave definido por Andrade e Rossetti (2004, p.29) é a gestão. Os aspectos centrais das práticas de gestão são derivados diretos das melhores práticas de governança corporativa. Três pontos centrais, fortemente ligados aos valores sustentam a governança: a) a integridade ética, permeando todas as relações internas e externas; b) o trinômio integridade, competência e envolvimento construtivos no trato dos negócios; e c) a responsabilidade corporativa, abrangendo um leque ampliado de interesses, para o qual convergem, em praticamente todos os países, os processos mais estratégicos e menos minimalistas de governança.

\subsection{A Controladoria frente à Governança Corporativa}

Para Martin (2002, p.13), a controladoria expressa o entendimento de que todos os recursos que são mobilizados e utilizados pelas organizações têm um objetivo maior: produzir valor.

Nesta perspectiva, a transformação produtiva, convertendo recursos em bens e ou serviços, pressupõe a existência de mercado e demanda econômica. Essa transformação de recursos gera custos e deve, conseqüentemente, com os seus produtos, produzir valor para os clientes e usuários, bem como para os acionistas e ou investidores.

O resultado econômico da empresa corresponde, portanto, à variação do seu patrimônio líquido. Essa variação é determinada tanto pela movimentação dos ativos e passivos, os quais referem-se, respectivamente a benefícios ou sacrifícios futuros de recursos econômicos, e têm, por origem, as decisões tomadas na empresa. Assim, a mensuração econômica dos recursos envolvidos deve permitir a escolha de alternativas que agregariam o melhor resultado econômico ao patrimônio da empresa.

Assim sendo, a Controladoria precisa ser intrinsecamente estratégica, para atender às necessidades da gestão moderna e incorporar as necessidades da própria natureza da empresa e de seus objetivos, bem como do ambiente em que ela está inserida e com no qual interage, tais como, mercado, concorrência e tecnologia.

Martin (2002, p.25), também apresenta as características atuais da controladoria . Ressalta, que as transformações recentes, no panorama mundial da contabilidade gerencial, têm imensas implicações para o ensino e na formação de controllers, ou seja, busca preparar estes profissionais com um perfil mais generalista, com capacidade de entender a empresa como um todo.

A Controladoria tem, entre suas atribuições, a função de organizar e reportar dados relevantes no processo decisório, desempenhando, portanto, um papel estratégico no conceito de accountability, suportado pelas teorias da decisão, mensuração e informação.

Uma das informações relevantes fornecidas pela Controladoria para tomada de decisão estratégica, trata-se do atendimento a níveis diferenciados de governança corporativa, como por exemplo, a adesão ou não ao Novo Mercado da Bovespa.

$\mathrm{Na}$ figura a seguir onde são apresentadas as características e funções da Controladoria, os níveis de decisão acabam por serem orientados pela consciência estratégica 
que traduz a missão da empresa na qual deve estar inserida a governança corporativa. A decisão final, com certeza, vai cotejar a informação e as características da empresa, envolvendo aspectos de sua gestão e centros de poder.

\section{METODOLOGIA DA PESQUISA E ANÁLISE DO RESULTADO}

Neste item, apresenta-se os procedimentos metodológicos e a análise do resultado da pesquisa de campo, efetuada junto a empresas com capital aberto que têm suas ações negociadas na Bovespa.

\begin{tabular}{|l|}
\hline CONSCIENCIA \\
ESTRATÉGICA \\
\hline \\
\hline Missão
\end{tabular}

\subsection{Metodologia da pesquisa}

Para atingir o objetivo do trabalho, foi realizada uma pesquisa de campo exploratória. Segundo Marconi e Lakatos (2003), a pesquisa de campo é aquela utilizada com o objetivo de conseguir informações ou conhecimentos acerca de um problema, para o qual se procura uma resposta, ou de uma hipótese, que se queira comprovar, ou, ainda, descobrir novos fenômenos ou as relações entre

Figura 3: Características da Controladoria

Fonte: Martin (2002, p. 25)

\subsubsection{Governança corporativa e o enfoque de custos}

A decisão de uma companhia de abrir o capital e de manter suas ações listadas nos segmentos de negociação do Novo Mercado e de Práticas Diferenciada de Governança Corporativa I e II da Bovespa, incorre numa série de custos e despesas explícitos e implícitos. Ferreira (1999) define o termo implícito como o que está envolvido, mas não de modo claro; portanto subentendido. Já o termo explícito, é definido como expresso formalmente, portanto claro.

Os custos denominados explícitos, são mais claros e facilmente mensuráveis, traduzem-se praticamente em despesas administrativas, tais como a contratação de advogados, auditores independentes, passando pelo pagamento de taxas junto à CVM e Bolsa de Valores e custos de publicações.

Os custos denominados implícitos, necessariamente não geram desembolsos de caixa, mas sim o custo de diminuição do poder dos controladores, principalmente, nas ditas empresas familiares. À medida em que são implantadas boas práticas de governança, as empresas que realmente desejarem ter uma gestão transparente, precisam adotar o compartilhamento de poder com outros acionistas (minoritários), a representatividade nos conselhos de administração e fiscal, a profissionalização da gestão (exclusão de membros das famílias), a obrigatoriedade de estender o tag along (conceder as mesmas condições das ações ordinárias às ações preferenciais) em condições que superam as normas previstas em lei; o compartilhamento do "prêmio de sinergia" com outros acionistas, a adesão à Câmara de Arbitragem para a solução de pendências, abrindo mão de recorrer ao Poder Judiciário (extremamente moroso), entre outros procedimentos. Estas atividades anteriormente destacadas, geradoras de custos implícitos, podem acabar também gerando despesas explícitas. eles. Gil (1999) define que pesquisas exploratórias são desenvolvidas com o objetivo de proporcionar visão geral, de tipo aproximado, a cerca de determinado fato. Este tipo de pesquisa é realizado especialmente quando o tema escolhido é pouco explorado e torna-se difícil sobre ele formular hipóteses precisas e operacionalizáveis.

$\mathrm{O}$ instrumento considerado mais adequado para o levantamento de dados em campo segundo Babbie (1999) e Cooper e Schindler (2003), foi a aplicação de um questionário estruturado com 14 perguntas fechadas.

O tipo de pesquisa que se mostrou mais adequado, foi a exploratória que segundo Sâmara e Barros (1997, p.24) têm como principal característica a informalidade, a flexibilidade e a criatividade, e neles procura-se obter um primeiro contato com a situação a ser pesquisada, ou um melhor conhecimento sobre o objeto em estudo.

O questionário submetido aos respondentes foi dividido em dois módulos. No primeiro módulo, procurou-se identificar junto aos profissionais entrevistados alguns aspectos qualitativos com destaque para: a) quais são os conceitos sobre governança corporativa considerados individualmente por empresa; b) como elas se enquadram nos padrões de exigências de governança corporativa dos níveis I, II e Novo Mercado da BOVESPA; c) que importância as empresas atribuem aos diferentes Códigos de Governança Corporativa existentes; d) como as empresas avaliam se as práticas de governança corporativa contribuem, ou não, para a melhor "precificação" de suas ações na BOVESPA; e) como deve ser a subordinação da estrutura do Departamento de Relações com Investidores (RI); f) como deve estar estruturado o sistema de informações da empresa; g) se o conhecimento dos custos com a governança corporativa seria um fator decisivo para as empresas aderirem ao Novo Mercado. 
No segundo módulo, procurou-se identificar como as empresas consideram os custos de algumas atividades ligadas à governança corporativa, com destaque para: a) abertura de capital da empresa; b) preparação de operação de captação de recursos no mercado acionário; c) custos relativos aos órgãos envolvidos com a governança corporativa; d) qual é o conhecimento que as empresas possuem sobre os custos das atividades envolvidos com a governança corporativa.

A amostragem foi determinada por acessibilidade (ou conveniência), que ainda segundo Gil (1999) é aquela que o pesquisador seleciona os elementos a que tem acesso, admitindo que estes possam, de alguma forma, representar o universo.

O universo de empresas (população) objeto do presente estudo é formado por 50 companhias abertas que possuem suas ações listadas para negociação na Bovespa em diversos graus de utilização de boas práticas de governança corporativa, representando $76 \%$ do valor total do patrimônio líquido das empresas integrantes daquela bolsa em 31.12.04. $\mathrm{O}$ instrumento de pesquisa foi encaminhado para os diretores de relações com investidores, gerentes de relações com investidores e diretores de controladoria .

Foram respondidos 30 questionários pelas empresas pesquisadas, dos quais 20 encontram-se atualmente listadas nos segmentos de Níveis Diferenciados de Governança Corporativa I e II e do Novo Mercado da BOVESPA, e as demais ainda estão analisando a adesão ao citado segmento.

\subsection{Análise do resultado da pesquisa}

A seguir são apresentadas as principais questões formuladas e uma síntese de suas respostas.

\begin{tabular}{|c|c|}
\hline NúM & O QUESTIONÁRIO \\
\hline $\begin{array}{l}\text { Questão } \mathbf{n}^{\mathbf{0}} \mathbf{1} \\
\text { Qual o conceito de governança corporativa } \\
\text { que mais se adapta a sua empresa? }\end{array}$ & $\begin{array}{l}\text { alta direção da companhia, acionistas e demais stakeholders é o que mais se } \\
\text { dapta a sua empresa. }\end{array}$ \\
\hline $\begin{array}{l}\text { Questão } \mathbf{n}^{\mathbf{0}} \mathbf{2} \\
\text { Qual o estágio de governança corporativa } \\
\text { praticado pela empresa? }\end{array}$ & $\begin{array}{l}\text { odas as companhias atendem aos requisitos mínimos exigidos pela legislação em } \\
\text { igor. As que já estão listadas no Novo Mercado atendem aos níveis exigidos pelos } \\
\text { egmentos de Níveis I e II e Novo Mercado da BOVESPA }\end{array}$ \\
\hline $\begin{array}{l}\text { Questão } \mathbf{n}^{\circ} \mathbf{5} \\
\text { Boas práticas de GC contribuem para } \\
\text { melhorar a imagem da empresa e se refletem } \\
\text { nas cotações das ações? }\end{array}$ & $\begin{array}{l}\text { Alcançada a média nove, em uma } \\
\text { tremamente importante). }\end{array}$ \\
\hline $\begin{array}{l}\text { Questão } \mathbf{n}^{\mathbf{0}} \mathbf{7} \\
\text { Qual a estrutura ideal para o funcionamento } \\
\text { do Depto de RI? }\end{array}$ & \\
\hline $\begin{array}{l}\text { Questão } \mathbf{n}^{\mathbf{0}} \mathbf{8} \\
\text { Como você vê a criação do Comitê de } \\
\text { Auditoria (Lei Sarbanes-Oxley)? }\end{array}$ & $\begin{array}{l}\text { riação do Comitê de Auditoria. Já } 21 \% \text { dos } \\
\text { funções do Comitê de Auditoria poderiam ser }\end{array}$ \\
\hline $\begin{array}{l}\text { Questão } \mathbf{n}^{\mathbf{9} 9} \\
\text { Qual a estrutura necessária ao sistema de } \\
\text { informações (controladoria e contabilidade } \\
\text { estratégica) para atender à demanda de } \\
\text { informações? }\end{array}$ & $\begin{array}{l}\text { Para 48\%; as informações fornecidas pela Contabilidade são centralizadas pela } \\
\text { Controladoria, e repassadas ao Conselho de Administração e Diretoria/Gerência de } \\
\text { Relações (DRI) com os Investidores. Para } 30 \% \text { dos entrevistados; as informações } \\
\text { fornecidas pela Contabilidade são centralizadas pela Controladoria, e repassadas } \\
\text { diretamente ao DRI. Os restantes } 22 \% \text { informaram que os sistemas são acessados } \\
\text { diretamente pelos diretores e gerentes. }\end{array}$ \\
\hline $\begin{array}{l}\text { Questão } \mathbf{n}^{\mathbf{0}} \mathbf{1 0} \\
\text { Quais são os fatores que inibem a adesão de } \\
\text { novas companhias ao Novo Mercado da } \\
\text { BOVESPA? }\end{array}$ & $\begin{array}{l}\text { Para } 80 \% \text { são inibidores os fatores implícitos: cultura familiar, problemas de } \\
\text { sucessão; compartilhamento de poder; conselhos de administração e fiscal } \\
\text { profissionais; exigências de "tag along", "free float" de } 25 \% \text {; e câmara de } \\
\text { arbitragem. Os restantes } 20 \% \text { consideraram como fatores inibidores os custos } \\
\text { explícitos (transparência,volume de informações). }\end{array}$ \\
\hline $\begin{array}{l}\text { Questão } \mathbf{n}^{\mathbf{0}} \mathbf{1 3} \\
\text { Qual o nivel de conhecimento das empresas } \\
\text { têm sobre os custos envolvidos na atividade de } \\
\text { governança corporativa? Estes custos e } \\
\text { despesas deveriam ser segregados? }\end{array}$ & $\begin{array}{l}\text { Para } 78 \% \text { o conhecimento dos custos com a atividade de governança corporativa } \\
\text { ainda é incipiente e somente } 22 \% \text { responderam que têm bom conhecimento desses } \\
\text { custos. Contudo, a maioria concorda que deveriam ser melhor analisados para } \\
\text { aumentar o nível das informações. }\end{array}$ \\
\hline $\begin{array}{l}\text { Questão } \mathbf{n}^{0} \mathbf{1 4} \\
\text { Se as empresas conhecessem os efetivos custos } \\
\text { de GC, poderia haver maior migração para o } \\
\text { novo mercado da Bovespa? }\end{array}$ & $\begin{array}{l}\text { Cerca de } 73 \% \text { dos respondentes consideraram que os custos implícitos são os mais } \\
\text { importantes na decisão. Porém, é importante conhecer também as despesas } \\
\text { explícitas, normalmente classificadas como despesas administrativas, para a } \\
\text { tomada de decisões mais consistentes. }\end{array}$ \\
\hline
\end{tabular}

Quadro 1: Principais questões e respostas da pesquisa de campo.

Fonte: elaborado pelos autores. 
Com base nas respostas da pesquisa de campo, verifica-se que existe uma convergência na opinião das empresas. Merecem destaque, no que está mais relacionado ao principal objetivo deste trabalho, as questões 10,13 e 14 .

$\mathrm{Na}$ questão 10 , cerca de $80 \%$ dos respondentes concordam que são fatores inibidores aqueles que acabam por reduzir o poder dos controladores, tais como problemas de sucessão, profissionalização da gestão; compartilhamento de poder; conselhos de administração e fiscais profissionais e exigência de tag along de $100 \%$ para as ações ordinárias e preferenciais.

Na questão 14 , cerca de $73 \%$ dos respondentes consideram que os fatores apontados na assertiva 10, que resultam nos custos implícitos, são os mais importantes no momento de decidir pela adesão ou não a níveis diferenciados de governança corporativa. Finalmente na questão 13, cerca de $78 \%$ dos respondentes informam que o conhecimento dos custos da governança corporativa é ainda incipiente. Estas respostas, analisadas conjuntamente, indicam que, apesar das empresas considerarem que os custos implícitos são os verdadeiros responsáveis pela não adesão, efetivamente, ainda não cotejaram as vantagens e desvantagens da referida adesão. Também contribui para esta situação a forte tendência familiar que predomina na gestão da maioria das empresas brasileiras, conforme exposto no referencial teórico.

Por outro lado, correlacionando-se a questão 2 onde todos os informantes já atendem aos requisitos mínimos exigidos pela legislação brasileira em vigor com a questão 5 , onde numa escala de 0 (nenhuma importância ) e 10 (extremamente importante), a média das respostas foi 9 e questão 8 onde $79 \%$ são a favor da criação do Comitê de Auditoria previsto na $S O X$, deduz-se que a grande maioria das empresas entende que a governança corporativa é muito importante para o seu sucesso. Contrapondo o teor destas respostas ao baixo nível de adesão (somente $12 \%$ ) aos níveis diferenciados de governança informado pela Bovespa, confirma-se mais uma vez que os fatores relacionados à cultura familiar, que se traduzem nos custos implícitos, são os verdadeiros motivos inibidores deste comportamento.

\section{CONCLUSÃO}

Inicialmente este trabalho procurou traçar a evolução histórica da governança corporativa, começando pelo período logo após a Segunda Guerra Mundial, quando ocorreu nos Estados Unidos um forte movimento das empresas abrindo seu capital e lançando suas ações no mercado acionário daquele país, visando financiar a expansão de suas atividades.

Esta decisão gerou o compartilhamento da propriedade acionária e pulverização do capital e também distorções geradas pela concentração de poder na mão de alguns gestores. Para frear estes atos, a SEC editou e vem editando normas que impõem salvaguardas a serem adotadas pelas empresas no sentido de proteger os investidores. No Brasil, apesar das normas editadas pela Comissão de Valores Mobiliários - CVM, a baixa dispersão acionária sempre favoreceu o controle familiar das empresas e suas conseqüentes distorções. Ainda hoje é possível encontrar, a gestão e a propriedade concentradas nas mãos do grupo controlador, e as principais funções administrativas sendo executadas por membros ligados à família ou a esse grupo.

Seguindo a evolução da governança corporativa, em 1985, com o ativismo do California Public Employes Retirement System (CalPERS), um dos principais fundos de pensão norteamericano e outras entidades, foi criado o Council of Institucional Investors (CII), marco inicial da governança corporativa nos Estados Unidos e no mundo.

O último grande movimento em prol da governança corporativa ocorreu após os escândalos que tiveram repercussão mundial envolvendo empresas de vários países, principalmente nos Estados Unidos. Em resposta a estas fraudes contábeis, o governo norteamericano editou em 2002 a Lei Sarbanes-Oxley (SOX) determinando novos controles e procedimentos, com a finalidade de oferecer maior transparência às transações e atos praticados.

O Brasil não ficou imune a este movimento e foi elaborado todo um conjunto de normas voltadas para este assunto. Neste contexto, destaca-se a Bovespa que criou os segmentos do Novo Mercado e de Práticas Diferenciadas de Governança Corporativa - Níveis I e II.

Considerando-se que existiam registradas, em dezembro de 2004, cerca de 400 companhias abertas para negociação de suas ações no mercado acionário brasileiro, e que destas, apenas um contingente de 47 empresas (12\%) haviam feito sua adesão aos segmentos de listagem de do Novo Mercado da Bovespa, o objetivo deste trabalho é identificar os fatores inibidores que justificassem este comportamento.

Para atender a este objetivo, foi realizada uma pesquisa de campo. As respostas da pesquisa realizada demonstram que a maioria das empresas entende que a transparência com o mercado é vantajosa, porém num contexto em que ainda predomina a "gestão familiar", alegam que o motivo para não aderirem aos Novos Mercados criados pela Bovespa - que pressupõem atendimento a níveis crescentes de governança - são os fatores que reduzem o poder do grupo controlador e que acabam por gerar custos implícitos, seja pela perda deste poder, seja pelo pagamento de dividendos adicionais ou seja pela aceitação da adesão à Câmara de Arbitragem para solução de pendências.

A seguir lista-se uma síntese das respostas do questionário em que os respondentes informam:

- atender os requisitos mínimos da governança corporativa, pois mesmo aquelas que ainda não aderiram ao Novo Mercado procuram atender aos requisitos mínimos da legislação legal;

- concordar que a governança corporativa é importante para o desenvolvimento e evolução das companhias; 
- concordar com a criação de estruturas voltadas para a governança, tais como o comitê de auditoria para que os atos de gestão possam ser melhor controlados;

- entender que as áreas de relacionamento com investidores devem ser municiadas com informações relevantes;

- relacionar a baixa adesão aos novos mercados da Bovespa aos "custos implícitos";

- admitir que existe desconhecimento sobre os custos e despesas da atividade de governança corporativa.

Finalmente, visando futuros trabalhos sobre o assunto, indica-se temas como a mensuração dos custos implícitos e as vantagens da adoção da governança; a implantação do Comitê de Auditoria; e custos e despesas com a implantação dos requisitos e procedimentos da Lei Sarbanes-Oxley.

\section{REFERÊNCIAS BIBLIOGRÁFICAS}

ANDRADE, A.; ROSSETTI,J.P. Governança Corporativa: fundamentos, desenvolvimento e tendências. São Paulo: Atlas, 2004.

BABBIE, E. Métodos de pesquisas de survey. Tradução de Guilherme Cezarino.Belo Horizonte: UFMG, 1999.

BOLSA DE VALORES DO ESTADO DE SÃO PAULO BOVESPA. Novo Mercado e Níveis 1 e 2 de Governança Corporativa. Disponível em: $\leq$ www.bovespa.com.br>. Acesso em 25 fev. 2005.

CARISSON, R. H. Owenership and Value Creation: strategic corporate governance in the new economy. New York: John Wiley and Sons Ltd. 2001.

CATELLI, A. (Coordenador) - Controladoria: uma abordagem de gestão econômica. São Paulo: Atlas, 1999.

COMISSÃO DE VALORES MOBILIÁRIOS - CVM. Recomendações da CVM sobre Governança Corporativa. - Disponível em: <www.cvm.gov.br>. Acesso em: 25 fev. 2005.
COOPER D. R.; SCHINDLER, P. S. Métodos de pesquisa em administração. 7.ed. Porto Alegre: Bookman, 2003.

FERREIRA, A.B.H. Aurélio século XXI: o dicionário da língua portuguesa.3.ed. Rio de Janeiro: Nova Fronteira, 1999.

GIL, A. C. Métodos e técnicas de pesquisa social. 5.ed. São Paulo: Atlas,1999.

GORGA,E. Does culturematterfor Corporate Governance? A case study of Brazil. Disponível em: $\leq$ ssrn.com>. Acesso em 25 feb. 2005

INSTITUTO BRASILEIRO DE GOVERNANCA CORPORATIVA, IBGC. Código das melhores práticas de governança corporativa. Disponível em: <www.ibgc.org.br $>$. Acesso em 15 jan.20

LODI, J.B. Governança corporativa: o governo da empresa e o conselho de administração. 3. ed. Rio de Janeiro: Campus, 2000.

MARTIN, N.C. Da contabilidade a controladoria: a evolução necessária. São Paulo. In, Revista Contabilidade e Finanças - n ${ }^{\circ} 28$. Universidade de São Paulo, jan./abr., 2002.

MARCONI, M.A.; LAKATOS, E.M. Fundamentos de metodologia científica. 5.ed - São Paulo: Atlas, 2000.

ORGANIZATION FOR ECONOMIC COOPERATION AND DEVELOPMENT - OECD. Principles of Corporate Governance. Paris: OECD, 1999

SAMARA, B.S.; BARROS, J.C. Pesquisa de marketing : conceitos e metodologia. São Paulo: Makron Books, 1997.

SOARES, R.C. Empresariedade \& ética: o exercício da cidadania corporativa. São Paulo: Atlas, 2002.

STEINBERG, H. A Dimensão humana da governança corporativa. São Paulo: Gente, 2003

WALD, A. O Governo das Empresas. Revista dos Tribunais, São Paulo, ano 5, n.15, p.53-78, jan./mar., 2002.

YAMAMOTO, M.M.; ALMEIDA PRADO, J. E. Governança e o valor das empresas. Revista Bovespa, São Paulo, n. 88, p. 42-43, 2003. 